\title{
A ESCOLA DE TEMPO INTEGRAL E O USO DO LAPTOP UCA
}

\author{
Nicoli da S. Sauchuk ${ }^{1}$, Lúcia M. D. Couto ${ }^{2}$ \\ Secretaria de Estado de Educação de Mato Grosso do Sul \\ ${ }^{1}$ Escola Estadual Roberto Scaff - Anastácio/MS \\ ${ }^{2}$ Núcleo de Tecnologia Educacional de Aquidauana \\ nssauchukegmail.com, luciamartinsdcegmail.com
}

Resumo. Este artigo descreve as novas práticas pedagógicas adotadas pela Escola Estadual Roberto Scaff, utilizando como recurso tecnológico os laptops do Projeto UCA. Por ser uma escola de tempo integral, os equipamentos vieram somar às novas práticas adotadas pelos docentes, diante dessa nova realidade. 